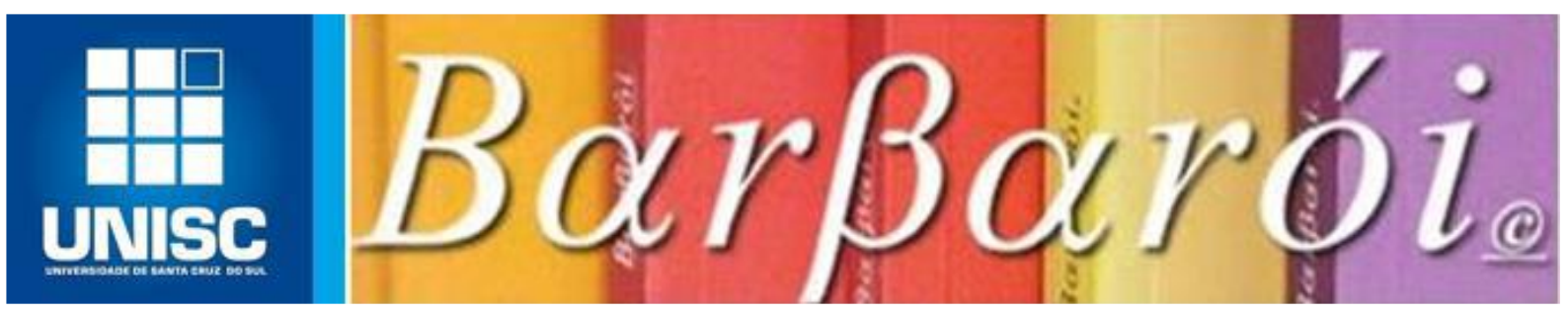

\title{
IMPLICAÇÕES DO DIAGNÓSTICO NO TRABALHO PEDAGÓGICO COM CRIANÇAS AUTISTAS: SENTIDOS E SIGNIFICADOS NO FAZER DOCENTE ${ }^{1}$
}

DOI: http://dx.doi.org/10.17058/barbaroi.v0i58.15558

\author{
$*$ \\ Wilian Gomes da Silva \\ Universidade Luterana do Brasil - ULBRA - Brasil \\ Simone Regina Sandri Modesti \\ Universidade Luterana do Brasil - ULBRA - Brasil
}

$*$

\section{Resumo}

No que tange à escolarização de crianças autistas, o debate sobre o diagnóstico tem sido central, circulando entre os docentes sem muitas interrogações e delineando os percursos escolares desses sujeitos. Neste artigo, de natureza qualitativa e exploratória, tivemos por objetivo discutir as implicações do diagnóstico no trabalho pedagógico com crianças autistas, buscando seus sentidos e significados no fazer docente. Para tanto, foram entrevistadas seis (6) professoras, de duas escolas, municipal e estadual, da Região Metropolitana de Porto Alegre/RS. Como instrumentos de coleta dos dados, utilizou-se de Roteiro de Entrevista Semiestruturada e Questionário Sociodemográfico. Os dados das entrevistas foram transcritos e analisados através da Análise Institucional do Discurso (AID). Como referencial teórico, utilizou-se dos aportes da psicanálise. Os resultados apontam ser o laudo médico-psicológico, para as professoras, fundamental na condução do trabalho, bem como para a disponibilização dos recursos escolares que o aluno tem direito.

Palavras-chave: autismo; educação especial; diagnóstico.

\section{Introdução}

Atualmente, no Brasil, a Educação Especial vem sendo regida pela Política Nacional de Educação Especial na Perspectiva da Educação Inclusiva (PNEEPEI) (BRASIL, 2008) que, em seu texto, define como público-alvo da Educação Especial (PAEE) alunos com deficiência motora ou sensorial (audição e visão, por exemplo) e aquelas, denominadas pela letra da lei,

\footnotetext{
${ }^{1} \mathrm{O}$ presente artigo, brevemente modificado, foi apresentado como Trabalho de Conclusão de Curso no dia 09 de julho de 2020, do Curso de Psicologia da Universidade Luterana do Brasil, Campus Gravataí/RS.

Barbarói, Santa Cruz do Sul, n. 58, p.<122-140>, jan/jun 2021
} 
como pertencentes à categoria de Transtornos Globais do Desenvolvimento (TGD). Define, também, o Atendimento Educacional Especializado (AEE) como suplementar ou complementar ao Ensino Regular (BRIDI, 2015), não substitutivo e devendo ser oferecido no contraturno escolar. Mais ainda, a política é transversal, contemplando desde a Educação Infantil até os níveis mais elevados de ensino (NEVES; RAHME; FERREIRA, 2019).

Os sujeitos com TGDs, na PNEEPEI (BRASIL, 2008), podem assim ser definidos: apresentam alterações qualitativas na interação social, linguagem, bem como, interesses restritos e comportamento estereotipado. Insere-se, então, nesse grupo, crianças com autismo e psicose infantil. No terreno da psicopatologia, o autista que se fala nas neurociências não é o mesmo da psicanálise. Na primeira corrente, imperam concepções organicistas, genéticas, ligadas a noção de déficit. Já para a segunda, teorizações que ora falam de traumas precoces, ora de uma posição subjetiva singular (VASQUES, 2015; VASQUES; MOSCHEN; GURSKI, 2013; VASQUES, 2009).

No que tange ao processo de escolarização de crianças autistas, foco desta pesquisa, o debate sobre o diagnóstico tem sido central, delineando os caminhos para o trabalho pedagógico (BRIDI, 2015; BRITO, 2015; VASQUES, 2015; VASQUES; MOSCHEN, 2012; VASQUES, 2009; VASQUES, 2008). Diagnosticar, termo oriundo da medicina, significa classificar, descrever, separar, organizar, ordenar, etc. Sinaliza para o que é, delimitando, também, o que não é (VASQUES, 2015). Na atual conjuntura, a ciência positivista não deixa espaço para a dúvida (HEINZ, 2007). Não admite o não-saber, a suposição.

Pais e professores solicitam avaliações ao médico neurologista, ao psiquiatra, ao fonoaudiólogo e ao psicólogo. Se agenciam técnicas e tecnologias que visam a normatização do sujeito (BRANDÃO et al., 2011; CAVALCANTI; ROCHA, 2007; LERNER; VOLTOLINI, 2015). Tomado como objeto, ele é esvaziado em sua subjetividade. O diagnóstico, cujo código é rascunhado em uma folha em branco, assinado e carimbado, vem tamponar o vazio, a falta de sentido (HEINZ, 2007).

Supõem, pelo significante que nomeia o transtorno, um saber totalizante (VASQUES; MOSCHEN; FRÖHLICH, 2014). O significante é entendido aqui, como as palavras que construirão um sujeito (CHEMAMA, 1995). O acontecimento pedagógico fica obliterado pela insígnia: ele é autista! Ele é psicótico! ficando o aluno refém das condições possíveis que sua própria nomeação o permite (SILVA; MELLO; SILVA, 2015; VASQUES, 2015; VASQUES; MOSCHEN, 2012). Se diz o que ele tem, mas pouco se fala sobre o que ele não tem (CAVALCANTI; ROCHA, 2007). 
Não raro, diante da notícia de um problema no desenvolvimento, os pais/professores podem deixar de investir libidinalmente em seus filhos/alunos. O diagnóstico porta um duplo: ao mesmo tempo que tranquiliza, pode, também, produzir efeitos iatrogênicos (BERNARDINO, 2017; BERNARDINO, 2007; COSTA; MEDEIROS, 2018). Destituído do lugar de filho/aluno idealizado, que espaço há para a sobrevivência desse ser?

São crianças que não olham, que gritam, giram objetos sem parar, fixados em um ponto determinado do ambiente, deambulantes, que não falam - ou falam sem intenção de se comunicar (JERUSALINSKY, 2017; VASQUES, 2008). Como aprendem essas crianças? São escolarizáveis? Devem elas estarem na escola? Questões que comparecem no território escolar. O diagnóstico circula entre os docentes sem muitas interrogações (VASQUES, 2015; VASQUES; MOSCHEN; GURSKI,, 2013; VASQUES, 2009). Na falta de borda, o clínico é chamado a falar e intervir. Os professores ficam reféns do dizer especialista, depositando neles a esperança para margear a experiência educativa (ARAÚJO, 2008; BRITO, 2015).

Com base nas reflexões apresentadas, o objetivo deste artigo é discutir as implicações do diagnóstico no trabalho pedagógico com crianças autistas, buscando seus sentidos e significados no fazer docente ${ }^{2}$. Assim como um bebê é acolhido e narcisado por um casal parental que o desejou (BERNARDINO, 2010; FREUD, 1996/1914; KUPFER, 2010), o aluno também precisa ser (VASQUES; MOSCHEN; FRÖHLICH, 2014). Sabe-se que o processo de inclusão não depende apenas do professor, mas de uma rede que envolve a família, a comunidade, a instituição escolar como um todo (MILMANN, 2017). Justifica-se, assim, a relevância deste estudo, ao oportunizar conhecer os discursos que circulam nas duas escolas, dando a ver os modos de saber e poder que ora obstaculizam o trabalho, ora são capazes de promover o surgimento do novo, suspendendo as certezas instituídas.

Em um primeiro momento apresentam-se os procedimentos metodológicos, seus instrumentos e método de análise. Após, apresentamos um recorte dos resultados emergidos do campo. Posteriormente, a partir de teóricos da psicanálise, discute-se, de forma crítica, a querela diagnóstica, seus usos e fins, interrogando sobre a sua pertinência no delineamento de uma educação dita especial.

\footnotetext{
${ }^{2}$ Entende-se o fazer docente como um conjunto de práticas reflexivas e de ação que envolvem desde o planejamento das aulas (com os objetivos a serem alcançados, metodologias de ensino, recursos necessários, etc.) até os processos avaliativos (SOUZA; LORENSINI, 2020).
}

Barbarói, Santa Cruz do Sul, n. 58, p.<122-14O>, jan/jun 2021 


\section{Procedimentos Metodológicos}

A presente pesquisa é de natureza qualitativa, de cunho exploratório, que se inspira na pesquisa de campo para a coleta dos dados (SILVEIRA; CÓRDOVA, 2009). Participaram da pesquisa, seis (6) professoras atuantes em duas (2) escolas públicas, municipal e estadual, da Região Metropolitana de Porto Alegre/RS, que têm em sala de aula regular alunos com diagnóstico, ou hipótese diagnóstica, de autismo. Como critério, privilegiou-se professoras que lecionassem na Educação Infantil e Ensino Fundamental (Séries Iniciais, do $1^{\circ}$ ao $5^{\circ}$ ano).

As participantes foram escolhidas por conveniência (CRESSWELL, 2010), ou seja, tratou-se de voluntárias que aceitaram participar da pesquisa. Também foi realizado contato, via e-mail e pessoalmente, com a Secretaria Municipal de Educação (SMED), sendo, posteriormente, dirigido à escola indicada. Foi apresentada à direção a proposta do trabalho, tendo, por fim, o aceite da mesma para sua realização.

Como instrumentos de coleta dos dados, foram utilizados: 1) Questionário Sociodemográfico, solicitando informações a respeito da formação dos professores (Magistério, Graduação e Pós-Graduação em nível Lato Sensu ou Stricto Sensu), tempo de trabalho na instituição, tempo de experiência no trabalho com o público-alvo da Educação Especial (PAEE), gênero, idade, etc.; e 2) Roteiro de Entrevista Semiestruturada, contendo um total de sete (7) perguntas que buscassem atingir os objetivos propostos na pesquisa. Foram apresentados, também, o Termo de Autorização para Uso de Voz (TAUV) e o Termo de Consentimento Livre e Esclarecido (TCLE) para Maiores de 18 anos, constando informações sobre a pesquisa.

Primeiramente, as participantes foram informadas sobre o TAUV, sendo explicado que a entrevista seria gravada e, após, transcrita em forma de texto, visando a análise do seu discurso. Em um segundo momento, passou-se a leitura do TCLE, apontando os objetivos da pesquisa, a fundamentação teórica, o seu papel enquanto participante, bem como, dos riscos e benefícios envolvidos. Estando as participantes de acordo com o exposto, assinaram os devidos termos, em duas (2) vias de igual teor, ficando uma em sua posse e outra em posse do pesquisador, conforme recomendações constantes na Resolução $\mathrm{n}^{\circ} 510$ do Conselho Nacional de Saúde (CNS, 2016). Após a assinatura dos termos, as participantes foram solicitadas a preencher o Questionário Sociodemográfico. Por último, iniciou-se a entrevista, individualmente, sendo gravada em dispositivo telefônico com gravador de voz embutido.

$\mathrm{O}$ uso da entrevista permitiu que as participantes falassem livremente sobre aquilo que entendiam sobre determinado tema/assunto, podendo emitir opiniões e questionamentos sobre 
o mesmo, expondo suas realidades (FRASER; GONDIM, 2004; VIEIRA et al., 2019). A coleta dos dados ocorreu em Março de 2020, mais especificamente nos dias 5, 10 e 13 do respectivo mês. As entrevistas tiveram uma média de duração de 22 minutos e 10 segundos, ocorrendo nas dependências das escolas (sala dos professores, biblioteca e sala de orientação). Após, foram transcritas (incluindo silêncios, repetições de letras e palavras) e tomadas como um texto a ser lido e interpretado.

Como método de análise, utilizou-se da Análise Institucional do Discurso (AID), de Marlene Guirado (2009), tendo por sustentações teóricas diferentes campos de saber, como: a psicanálise, a análise do discurso francesa e a filosofia. Para a autora, o discurso é produzido dentro de um contexto/instituição que possibilitam as condições para sua enunciação. Portanto, é na instituição que se produz o discurso, dando a ver os jogos de poder-saber que ora legitimam, ora deslegitimam aquilo que nela circula. Viaro e Valore (2011) apontam que o discurso pode ser vivenciado tanto externamente quanto internamente, tecido no cerne das relações interpessoais e institucionais, ordenando o saber. Logo, o discurso não é apenas um falatório, mas um modo de agir capaz de afetar e resistir na própria produção dela mesma.

Os resultados apresentados referem-se a um recorte de um projeto intitulado "A caminho da escola: discursos de professores sobre a escolarização de crianças ditas autistas", aprovada pelo Comitê de Ética e Pesquisa com Seres Humanos (CEP) da Universidade Luterana do Brasil (ULBRA), pelo Parecer 3.940.075, CAEE 28695120.6.0000.5349, que teve por objetivo geral: investigar os desafios vivenciados por professores na escolarização de crianças ditas autistas de quatro (4) a doze (12) anos. Visando a preservação da identidade das participantes, assim como, das instituições envolvidas, seus nomes foram omitidos. As participantes são aqui identificadas com a letra "P", de professora, seguido de número correspondente, por exemplo, P1, P2, P3... e assim sucessivamente.

\section{Resultados}

Das participantes do estudo

Todas se identificaram como sendo do gênero feminino, com tempo de trabalho na escola entre 2 meses e 10 anos, e idades variando entre 20 e 48 anos. No que tange a formação acadêmica: P1 tem Magistério e formação superior em Letras e Pedagogia, além de especialização em Mídias na Educação; P2 é Licenciada em Pedagogia; P3 está concluindo seu curso, Licenciatura em Matemática; P4 é acadêmica de Licenciatura em Geografia; P5 é formada em Pedagogia com especialização em Educação Especial Inclusiva, assumindo as 
funções de professora de Séries Iniciais e também de Orientadora Educacional na escola em que atua e; por fim, P6, recém-graduada em Pedagogia.

Quanto ao tempo de trabalho com alunos público-alvo da Educação Especial, esse varia entre um (1) ano e cinco (5) anos. Uma das participantes não informou esse dado. O Quadro 1 apresenta o que aqui foi descrito.

Quadro 1 - Dados Sociodemográficos das Participantes

\begin{tabular}{|c|c|c|c|c|c|c|}
\hline & Gênero & Idade & $\begin{array}{c}\text { Tempo de } \\
\text { Exp. com } \\
\text { alunos PAEE } \\
\text { (anos) }\end{array}$ & $\begin{array}{l}\text { Turmas de } \\
\text { Atuação }\end{array}$ & Formação & $\begin{array}{l}\text { Cargo } \\
\text { Ocupado }\end{array}$ \\
\hline P1 & $\mathrm{F}$ & 29 & Não informado & $\begin{array}{l}\text { Ed. Inf. e Ens. } \\
\text { Fund. (Séries } \\
\text { Iniciais) }\end{array}$ & $\begin{array}{c}\text { Magistério } \\
\text { Licenciatura em Letras e } \\
\text { Pedagogia Especialização } \\
\text { em Mídias na Educação }\end{array}$ & $\begin{array}{l}\text { Professora de } \\
\text { Anos Iniciais }\end{array}$ \\
\hline $\mathbf{P 2}$ & $\mathrm{F}$ & 48 & 2 & $\begin{array}{l}\text { Ens. Fund. } \\
\text { (Séries } \\
\text { Iniciais) }\end{array}$ & $\begin{array}{l}\text { Licenciatura em } \\
\text { Pedagogia }\end{array}$ & Professora \\
\hline P3 & $\mathrm{F}$ & 23 & $\begin{array}{c}1 \text { ano e } 5 \\
\text { meses }\end{array}$ & $\begin{array}{l}\text { Ens. Fund. } \\
\text { (Séries } \\
\text { Iniciais) }\end{array}$ & $\begin{array}{c}\text { Licenciatura em } \\
\text { Matemática (em curso) }\end{array}$ & Professora \\
\hline P4 & $\mathrm{F}$ & 20 & 2 & $\begin{array}{l}\text { Ens. Fund. } \\
\text { (Séries } \\
\text { Iniciais) }\end{array}$ & $\begin{array}{l}\text { Licenciatura em Geografia } \\
\text { (em curso) }\end{array}$ & $\begin{array}{c}\text { Professora do } 4^{\circ} \\
\text { ano }\end{array}$ \\
\hline P5 & $\mathrm{F}$ & 28 & 5 & $\begin{array}{l}\text { Ens. Fund. } \\
\text { (Séries } \\
\text { Iniciais) }\end{array}$ & $\begin{array}{c}\text { Licenciatura em } \\
\text { Pedagogia } \\
\text { Especialização em } \\
\text { Educação Especial } \\
\text { Inclusiva } \\
\end{array}$ & $\begin{array}{l}\text { Orientadora } \\
\text { Educacional e } \\
\text { Professora }\end{array}$ \\
\hline P6 & $\mathrm{F}$ & 35 & 1 & $\begin{array}{l}\text { Ens. Fund. } \\
\text { (Séries } \\
\text { Iniciais) } \\
\end{array}$ & $\begin{array}{l}\text { Licenciatura em } \\
\text { Pedagogia }\end{array}$ & Professora \\
\hline
\end{tabular}

Fonte: os autores.

Descritos os dados das participantes do estudo, apresentam-se os resultados oriundos das entrevistas e, no que segue, a discussão referente a essas. Como eixo de análise, toma-se os discursos acerca do diagnóstico e suas implicações no trabalho pedagógico em sala de aula. Assim sendo, duas perguntas do Roteiro de Entrevista Semiestruturada foram cruciais para a elucidação do que aqui está exposto, a saber, as questões três e seis. A questão três (3) perguntava sobre a importância, ou não, dada ao laudo médico/psicológico/pedagógico para o trabalho em sala de aula e para a estruturação de um plano de atividades a ser desenvolvido. Já a questão seis (6) buscava compreender, a partir do discurso das professoras, se havia alguma diferença entre trabalhar com uma criança que já possuía um diagnóstico fechado para autismo com aquela que percebiam que tinha algo (em termos comportamentais, cognitivos, por exemplo), mas não sabiam muito bem o que era. 
Ter ou não ter laudo? Eis a questão!

Nas andanças pelos corredores escolares, entre um espaço e outro, entrevistando professoras com diferentes percepções sobre o tema, algo em comum ressoou em seus discursos: o diagnóstico de seu aluno. Nomeação que parece aplacar o mal-estar quando se trata da escolarização de crianças que apresentam impasses em sua estruturação psíquica.

Uma das professoras sinaliza a angústia que lhe desperta o não saber sobre seu aluno. Em sua fala, diz sobre o "tipo de autismo", sendo ele o que irá dar as condições para a sua investigação pessoal, demarcando o que pode ou não propor enquanto atividade, na intenção de ajudar seu aluno.

[...] tendo o diagnóstico da criança, sabendo o que ela tem né, o tipo de autismo, por exemplo, né, a gente já consegue meio que ir atrás, em busca né. E quando se tem uma criança que tu não tem laudo, que tu não tem diagnóstico, que tu não sabe o que que é, tu fica angustiada com... com aquela questão, né, e a gente quer ajudar, né, e se o professor é interessado, ele quer ajudar (P1, 05 de março de 2020).

Em outra resposta, semelhante a de P1, a professora diz tomar o laudo e, a partir dele, pensar em uma intervenção pedagógica, adaptando-o no dia a dia, junto ao aluno.

\begin{abstract}
Eu tento procurar o laudo dele e ao mesmo tempo a gente vai acompanhando ele no dia a dia, pra ver os limites de conhecimento dele, pra ver até que ponto posso... eu consigo chegar nele, né. Que não adianta eu passar muita informação, se ele também não consegue absorver muita coisa ao mesmo tempo. Então, eu pego o laudo dele, tento adaptar no dia a dia com ele (P6, 13 de março de 2020).
\end{abstract}

As professoras pareciam se desautorizar em sua prática, depositando suas esperanças e anseios no laudo médico-psicológico. O diagnóstico que aquele aluno porta direciona o trabalho a ser realizado. Em suas falas, era a peça-chave no delineamento de uma educação especializada. Por meio dele é que se sentiam autorizadas a buscar materiais para se trabalhar em sala de aula, saber mais sobre o que se passa com o aluno, quais atividades desenvolver ou não. Isso fica explícito nas falas de P2 e P4:

[...] quando tu tem o diagnóstico, já fechado, daquele aluno, tu consegue pesquisar, tu vai em busca... E tu pode 'olha, eu tenho um aluno assim, o que que... ah, eu já trabalhei dessa forma e foi bom'. Tu consegue ter. Agora quando tu não tem nada, tu tem uma criança que não tem nada, inclusive, assim, essa criança tem dificuldade de aprendizagem? Não, ela não tem. Ela tem que ter um diagnóstico. Tu não sabe por que caminho tu vai seguir. Porque se eu sei que ele é autista, eu vou correr um caminho, né, eu vou correr um caminho. Se ele for só disléxico? Tenho outra situação pra atender, né. Então, eu acho que, sim, é muito importante o diagnóstico, fechado, porque pode ter o melhor pra trabalhar (P2, 10 de março de 2020).

[...] se tu tem o laudo, tu sabe exatamente o que ele tem, tu vai lá e pesquisa como lidar com aquele, com aquela deficiência que ele tem e se ele não tem, se ele não foi ainda fazer a consulta, não tem um médico, a gente tem que adivinhar né (risos), basicamente assim, tem que ir tentando e vendo o que que é, mas é muito mais fácil quando tem o diagnóstico (P4, 13 de março de 2020).

Barbarói, Santa Cruz do Sul, n. 58, p.<122-140>,jan/jun 2021 
As participantes falam de caminhos diferentes, já que a depender do que tem aquela criança, se vai para um lado ou para o outro. Sem este recurso - seria o laudo um recurso? -, as professoras se sentem perdidas. Como bem pontua P4, "a gente tem que adivinhar", "ir tentando e vendo o que que é”. Situação que parece imobilizar, paralisar as apostas naquele aluno, provocando estranheza e o sentimento de impotência nas docentes. Por outro lado, sem ele não se tem como requisitar a monitora para auxiliar a professora em sala de aula, o uso da Sala de Recursos, a aprovação do aluno, mesmo que ele não tenha conseguido atingir as competências e habilidades requeridas para passar de ano.

\begin{abstract}
Ah, ela é muito importante! Porque tu vê, eu tenho muitos alunos que, às vezes, por não ter o diagnóstico, não tem direito a uma monitora, a um trabalho, ãnn, mais específico, até mesmo aprovação no final do ano. Como não tem diagnóstico, ele é deixado ali, ele é reprovado, até o terceiro ano, ele é reprovado, muitas vezes são reprovados... um, dois, três... quando tu vê, essa criança tá com uma idade bem diferente dos outros. Então eu acho que o diagnóstico, ele te possibilita essa... no final do ano ele ser promovido, mesmo sem aprendizagem. Então o diagnóstico, ele vem nos dar [inaudivel], a gente pode fazer umas aulas separadas, pode exigir monitor pra essa criança que vai estar ali, sozinho (P2, 10 de março de 2020)
\end{abstract}

[...] se a gente não tem o laudo daquele aluno, a gente não consegue que ele tenha alguns direitos na escola, como monitor e o uso da Sala de Recursos. Então, com o laudo é um... fundamental! A gente precisa que ele tenha aquele laudo pra que possa ter direto até na questão da reprovação, do nosso olhar, porque um aluno dito normal, ele precisa atingir, ãnn, aquela média final. E quando a gente entende que o aluno tem, ãnn, uma restrição, uma deficiência, a gente tem um outro olhar pra ele. Mas, a lei só ampara se ele tiver o laudo. Então o laudo é fundamental. Não tem como a gente dar um atendimento de qualidade pra aquele aluno se ele não tiver o laudo. Então, eu vejo, assim, como fundamental, o laudo, pra sala de aula e pra vida como cidadão (P5, 13 de março de 2020).

P5 coloca que, para ela, o laudo é um instrumento "fundamental" que possibilita às famílias e a própria criança acessar seus benefícios e direitos garantidos por lei. Será possível "dar um atendimento de qualidade" na escola.

No transcorrer da entrevista com P3, concluinte da Licenciatura em Matemática, recémchegada, estando apenas dois meses na instituição, tal questionamento, que aqui é colocado, se fez presente. A mesma se interroga sobre a necessidade de um laudo para saber sobre seu aluno, dizendo que cabe ao professor conhecer a todos. Diz se sentir confusa e aponta para a importância de pesquisas como a nossa para permitir essa descolagem ao laudo.

Assim, eles têm todos, tem a dificuldade assim, mas eu acho que com o laudo fechado a gente já tem, a gente já sabe o que pode fazer pra ajudar. 'Ah aquela criança tem autismo e déficit de atenção', a gente sabe que tem que trabalhar no déficit de atenção ali por que senão eles vão esquecendo a letrinha. 'Ah aquela criança é só autista e hiperativa', a gente já sabe que tem que trabalhar, pra mim eu acho que se a gente tem o laudo é mais, não é que é mais fácil, mas ééé, a gente consegue mais, ãnn, achar um modo entendeu de fazer, de ensinar eles. Já aquela criança que a gente não, que

Barbarói, Santa Cruz do Sul, n. 58, p.<122-140>, jan/jun 2021 
a gente percebe que tem, mas a gente não sabe o que, a gente não tem como, ãnn, a gente não sabe qual recurso usa, mas, ãnn, também tem aquela coisa, ah tu percebeu que ele, ãnn, não tem o laudo, mas percebeu que ele tem déficit de atenção porque ele não fixa aquela letrinha que tu tá falando, que é ' $u$ ', tu pergunta se é o ' $u$ ' depois tu volta e pergunta se é o ' $u$ ' de novo e ele fala que não é né? Como professora a gente já percebe um pouco, a gente já consegue também. É, tem toda aquela coisa ééé, eu acho que eu fico de coração dividida assim, depende do caso a gente fica com laudo a gente consegue, mas também tem aquele caso que a gente é professora, a gente quer conhecer os nossos alunos, antes... dentro da sala, como qualquer outro aluno. A gente tem que entender que, ãnn, a gente tem que saber ensinar eles. Então, é eu acho que eu fico com dois corações, eu acho que, é não sei... porque como professora também tem aqueles alunos, ãnn, que a gente tem que entrar na sala, 'ah vamos fazer essa atividade' e eu entender que aquele aluno não consegue. A gente tem que tentar conhecer nossos alunos, a gente tem que tentar, não precis... na verdade né, eu acho que não precisa de um laudo, a gente que tem que conhecer... Nossa ficou muito confuso agora, se parar pra pensar, é não sei agora... [continua]

Entrevistador: Que bom que a gente possibilita certas questões, de se questionar...

A gente se questionar né? É bom essas pesquisas que daí a gente vem e se questiona, porque senão a gente fica só naquele 'ah a gente tem que ter o laudo pra pensar como', mas a gente como professor, a gente tem que conhecer todos os nossos alunos, na verdade. Então a gente tem que entender que cada um tem, por que nem todos, não são todos, eles não tem o mesmo modo de pensar, o mesmo modo de ser. Então não tem na verdade diferença entre... a gente que tem que conhecer eles, é eu acho que é isso... não precisa de laudo (P3, 13 de março de 2020).

A certeza, supostamente assegurada, toma aqui outra dimensão. A figura do professor ganha protagonismo na fala da participante, demandando dele outra posição: o de se interrogar sobre seu aluno, sobre seus modos de aprender e se relacionar. Conhecer um aluno implica estar com ele, no dia a dia, em sala de aula e nos outros espaços da escola por onde circula: " [...] a gente tem que conhecer eles, é eu acho que é isso... não precisa de laudo".

\section{Discussão}

Não é de hoje que a Educação e a Psicanálise são colocadas em um mesmo texto, fazendo interlocuções e demarcando limites entre uma e outra. Mais recente é o diálogo desse saber com a Educação Especial, sendo seus estudos ainda incipientes (MOSCHEN; GURSKI; VASQUES, 2015). O que teria a Psicanálise a oferecer a esse campo? Podemos dizer, resgatando Voltolini (2011), que a mesma se propõe a destituir o lugar da Pedagogia como único campo do saber a falar sobre os assuntos atinentes à Educação. A Pedagogia - e porque não, a própria Psicanálise - não podem tudo, estando sujeitas, também, aos seus próprios limites.

A escola, enquanto instituição social, se vê encarregada de formar sujeitos para a sociedade, lidando com expectativas (ideal) quanto a sua função: a de capacitar crianças e adolescentes para o mercado de trabalho, para a vida, para o exercício de uma profissão, para passar no vestibular e ingressar na universidade, etc. (MILMANN, 2003). Segundo a autora, 
essa precisa se haver com a diferença que comporta a todos. Em outras palavras, precisa acolher, também, aquelas que apresentam impasses em sua estruturação psíquica devido a problemas de natureza orgânica, genética ou psíquica.

Quando da entrada de crianças e adolescentes que apresentam Transtornos Globais no Desenvolvimento (autistas e psicóticas), a menção ao laudo, que rubrica o diagnóstico, tem circulado pelos espaços escolares (BRIDI, 2015; BRITO, 2015; VASQUES, 2009; VASQUES, 2008). Não diferente, tal posição fez eco nos discursos das professoras entrevistadas, em que reclamam seu uso para que seus alunos possam ter direitos: à monitoria, ao currículo adaptado, a aprovação no final do ano e ao uso da Sala de Recursos, por exemplo.

Sabemos, por meio da Nota Técnica nº 04 (BRASIL, 2014) do Ministério da Educação e Cultura (MEC), que para acessar o AEE, bem como, outros recursos, a apresentação de laudo médico-psicológico é dispensável (MILMANN, 2017). O atendimento prestado no interior das instituições de ensino não é de caráter clínico, mas sim, pedagógico. Nesse sentido, a afirmação de P5 precisa ser questionada: "Mas, a lei só ampara se ele tiver o laudo. Então o laudo é fundamental". De que lei se fala? Fundamental para quem? Parece estarmos lidando, aqui, com o desconhecimento da própria legislação.

O que assistimos, atualmente - se é que podemos definir tal fenômeno como atual -, é a infiltração do discurso médico-psicologizante no cenário educativo, sendo chamado a responder às demandas que emergem dos processos de ensino-aprendizagem ou daqueles decorrentes do campo comportamental (ARAÚJO, 2008; BRITO, 2015). Professores e, porque não, os próprios pais, têm se desautorizado em seu saber, depositando suas esperanças e anseios na palavra do especialista, que supostamente teria algo a dizer sobre seu filho/aluno (BERNARDINO, 2016). Requerem técnicas de estimulação e atividades específicas a serem desenvolvidas. Apelam, enfim, para o uso de tecnologias como o Treatment and Education of Autistic and Related Communication-handicapped Children (TEACCH) (KUPFER, 1997), por exemplo, que pretendem normatizar, regular, padronizar, arquitetar e maximizar a funcionalidade do sujeito (ARAÚJO, 2008; BERNARDINO, 2010; BERNARDINO, 2007; BRANDÃO et al., 2011; CAVALCANTI; ROCHA, 2007).

Impera, assim, uma espécie de apagamento do sujeito, objetificando-o. Sua subjetividade é deixada de lado, sendo referido ao que tem ou deixa de ter, pouco importando o seu desejo (BERNARDINO, 2010; BERNARDINO, 2007; VASQUES, 2015). No campo da psicopatologia não há consensos. Em se tratando de autismo e psicose, são múltiplas as teorias que visam explicar e dar sentido aos gestos, aos comportamentos, a linguagem, aos olhares, aos 
silêncios, aos ditos e não ditos. Campo de tensão, que envolve disputas sobre quem detêm, ou não, o saber sobre a matéria. O sentido unívoco é ilusório, pontua Vasques (2009; 2008).

Nossas concepções essencializadas de infância imprimem, no plano pedagógico, certa linearidade no desenvolvimento: espera-se que atinja determinados marcos esperados para sua idade; aprenda de acordo com seu nível cognitivo atual; seja capaz de fazer cálculos matemáticos, ler e escrever em dado tempo cronológico (MILMANN, 2003). Toda aquela que não atinge o esperado, por diversas razões, adquire um signo em forma de rótulo. Como profecia, passa a definir as (im)possibilidades em seu percurso escolar (VASQUES; MOSCHEN, 2012).

Para as concepções biomédicas e organicistas, os comportamentos se traduzem enquanto déficits, alterações genéticas e desequilíbrios bioquímicos. O sujeito é submetido a aplicação de uma série de escalas e avaliações padronizadas, cujo resultado é emoldurado em um check-list, definindo em qual das tantas nomenclaturas se adequará. Se é autista, é preciso especificar o nível de suporte: nível 1, 2 ou 3. Se existem comorbidades, é preciso referir (VASQUES; MOSCHEN; GURSKI, 2013; VASQUES, 2009; VASQUES, 2008). Somente assim se poderá traçar planos e estratégias educativas que possam potencializar, ou não, a aprendizagem de tais sujeitos (BRIDI, 2015). Se isso está garantido, é outra história. Concepções que surgem nas falas de P1 e P6: “[...] sabendo o que ela tem né, o tipo de autismo, por exemplo, né, a gente já consegue meio que ir atrás, em busca né”, dirá a primeira; “[...] 'Ah aquela criança tem autismo e déficit de atenção', a gente sabe que tem que trabalhar no déficit de atenção ali por que senão eles vão esquecendo a letrinha. 'Ah aquela criança é só autista e hiperativa', a gente já sabe que tem que trabalhar, pra mim eu acho que se a gente tem o laudo é mais, não é que é mais fácil, mas ééé, a gente consegue mais, ãnn, achar um modo entendeu de fazer, de ensinar eles", responderá a segunda.

$\mathrm{Na}$ contramão do discurso hiperespecializado da ciência (BERNARDINO, 2007; NEVES; RAHME; FERREIRA, 2019) - ou coadunando com ela - a Psicanálise vem descentrar o sujeito de sua própria casa. O sujeito da razão não existe. A aceitação da noção de inconsciente nos coloca frente a um sujeito dividido, barrado, cujo gozo não está totalmente acessível (KUPFER, 2010; LERNER; VOLTOLINI, 2015). Há sempre algo que escapa das tentativas de captura e apreensão. Em outras palavras, há sempre algo do real que resiste à significação (VASQUES, 2009). Para os autores desse campo de saber, o autismo diz respeito a posição do sujeito na estrutura da linguagem e em relação ao Outro (KUPFER, 2010). Se trata mais de uma falha na operação simbólica do que um déficit perceptivo/cognitivo. O Outro é sentido como 
intrusivo/invasor, não sendo possível alienar-se, condição fundamental para a constituição subjetiva e da imagem corporal do infans (JERUSALINSKY, 2017; PIMENTA, 2019; VORCARO, 2016).

Ao apresentar as diferentes formas de ler e interpretar o (des)humano, não se trata de oferecer essa ou aquela teoria (VASQUES, 2009) como forma de aplacar a angústia que o encontro com o outro, estranho-familiar, nos suscita (SILVA; MELLO; SILVA, 2015). Mas, sim, de reconhecer e dar relevo as pluralidades epistêmicas que visibilizam um dizer sobre o sujeito da educação especial. Sujeito esse que nos interroga, que nos convoca a olhar, a observar, a deduzir, enfim, a estar com.

Defende-se, aqui, uma descolagem do significante autista, abrindo brechas para o surgimento de outros significantes que possam dizer sobre esse sujeito. A criança, quando inserida no contexto escolar, entra em contato com elementos da cultura infantil (PEREIRA; FIGUEIREDO, 2017). Um deslocamento se opera: não se passa mais a falar sobre sua patologia/posição subjetiva, mas sim, da sua vida escolar, das atividades que realizou naquele dia, das brincadeiras e trabalhos em grupo. Mudança subjetiva que faz deslizar outros modos de ler e interpretar o outro. O/A professor/a, quando não se deixa capturar pela doença de seu aluno, assume seu compromisso ético-político: o de se implicar e se responsabilizar pelo trajeto escolar do mesmo (PEREIRA; FIGUEIREDO, 2017; VASQUES, 2009; VASQUES, 2008).

Não há garantias prévias antecipadas pelo diagnóstico, devendo os atores que compõem a instituição escolar possibilitarem as condições para a circulação destes alunos (VASQUES, 2009; VASQUES, 2008). Requer uma posição que dispensa um saber a priori, requerendo a construção e invenção de outras vias e dispositivos junto à criança. Na falta ou excesso de recursos, métodos e técnicas, é preciso profanar seus modos de uso (MOSCHEN; GURSKI; VASQUES, 2015). As certezas precisam dar margem para as dúvidas. Supor um saber no outro, nem sempre acessível à primeira vista. Requer observação, respeito e paciência. O laudo, assim sendo, não pode e não deve ser balizador do trabalho pedagógico.

Como bem formula P3, "a gente tem que conhecer nossos alunos". O caminho, supostamente assegurado, conforme relatado por P2, encontra aqui certa resistência. É preciso estar disponível para o acontecimento, para aquilo que somente o encontro é capaz de produzir. Encontro, por vezes sozinho, mas também, em coletivo: envolve a gestão, as merendeiras, as tias da limpeza, o monitor de sala, os colegas de classe, a família e a comunidade como um todo. 


\section{Considerações Finais}

Como apresentado, teve-se por intenção, neste trabalho, discutir as implicações do diagnóstico no trabalho pedagógico com crianças autistas, buscando seus sentidos e significados no fazer docente. Conforme a revisão da literatura, o diagnóstico tem sido central quando se trata de falar sobre a escolarização de alunos com TGDs. Não diferente, sua menção fez eco nos discursos das professoras entrevistadas. Parecem desautorizar-se em seu saberfazer, delegando ao saber especialista um dizer que possa delinear os possíveis e impossíveis no percurso escolar de tais crianças. Tomam o laudo como condutor de suas práticas, bordeando os caminhos a serem seguidos. Mais ainda, o laudo é requerido para que o aluno possa ter os recursos em sala de aula: à monitoria, a aprovação no final do ano, o uso da Sala de Recursos, etc.

O diagnóstico não é capaz de antecipar algo sobre o aluno que ali se apresenta, pois há sempre algo que resiste às tentativas de captura e apreensão. Quando não questionado, pode produzir efeitos iatrogênicos por onde circula. Nesse sentido, é preciso perturbar as noções naturalizadas sobre infâncias, permitindo a abertura para outros modos de ser e estar no mundo. E não só: é preciso, também, ressignificar as formas de ler e interpretar o outro; de ensinar e de transmitir. É preciso apostar e construir com a criança, em sua singularidade.

Quando os recursos não forem suficientes ou as tecnologias não se adequarem aos seus modos de uso, é preciso inventar outras formas de usar. Posição ética que requer, antes de tudo, de disponibilidade: para se afetar, para estranhar, para se interrogar e construir hipóteses. Hipóteses que abrem outros mundos, outras formas de saber-fazer com o sujeito da educação especial. Assim sendo, a reflexão crítica e implicada precisa fazer parte do trabalho docente, bifurcando saberes totalizantes, abrindo brechas que permitam seguir outros caminhos: mais humanizados, justos e respeitosos.

Não se teve por meta, aqui, esgotar o debate, visto ser o tema complexo e de difícil consenso entre as múltiplas áreas. Segundo Heinz (2007), as diferentes linguagens, não raras vezes, obstaculizam o diálogo. Diálogo que hoje é necessário e emergente. Como contribuição, sugere-se para as escolas participantes desta pesquisa, a proposta para a realização de rodas de conversa que se proponham a escutar estes profissionais que trabalham com alunos PAEE, oferecendo um espaço de acolhimento e trocas, por onde a palavra possa circular. Não quer dizer que servirá a todos os contextos, muito menos que resolverá todos os problemas colocados por diferentes realidades, mas poderá permitir a reflexão sobre outros modos de trabalhar com tal público. 
Como limitações, acreditamos ser necessário a ampliação da amostra e a realização de pesquisas em outras escolas, contemplando, também, as particulares, possibilitando uma comparação entre diversificadas realidades. Pistas que podem conduzir outros estudos/escritas e propostas de trabalhos interdisciplinares. Parafraseando Voltolini (2011), a melhor educação é a que fracassa, pois é ela que permite a entrada do novo. Novo que não é estático, mas que se reinventa a cada desafio posto à escola.

\title{
IMPLICATIONS OF DIAGNOSIS IN PEDAGOGICAL WORK WITH AUTISTIC CHILDREN: SENSES AND MEANINGS IN TEACHING
}

\begin{abstract}
Regarding the schooling of autistic children, the debate about the diagnosis has been central, circulating among teachers without much questioning and outlining the school paths of these subjects. In this article, of a qualitative and exploratory nature, we aimed to discuss the implications of the diagnosis in the pedagogical work with autistic children, looking for their senses and meanings in teaching. For that, six (6) teachers from two public schools were interviewed, in which one school is municipally run and the other one is state-run, from the Metropolitan Region of Porto Alegre/RS. As instruments for data collection, a Semi-structured Interview Guide and Sociodemographic Questionnaire were used. The interview data were transcribed and analyzed using the Institutional Discourse Analysis (IDA). As a theoretical framework, contributions from psychoanalysis were used. The results indicate that the medicalpsychological report, for the teachers, is fundamental in the conduction of the work, as well as for the availability of school resources that the student is entitled to.
\end{abstract}

Keywords: autism; special education; diagnosis.

\section{IMPLICACIONES DEL DIAGNÓSTICO EN EL TRABAJO PEDAGÓGICO CON NIÑOS AUTISTICOS: SIGNIFICADOS Y SIGNIFICADOS EN LA ENSEÑANZA}

\section{Resumen}

Con respecto a la escolarización de los niños autistas, el debate sobre el diagnóstico ha sido central, circulando entre los docentes sin mucho cuestionamiento y delineando el camino educativo de estos sujetos. En este artículo, de naturaleza cualitativa y exploratoria, buscamos discutir las implicaciones del diagnóstico en el trabajo pedagógico con niños autistas, buscando sus sentidos y significados en la enseñanza. Para ello, se entrevistó a seis (6) docentes de dos escuelas, municipales y estatales, de la Región Metropolitana de Porto Alegre/RS. Como instrumentos para la recolha de datos, se utilizaron una Guía de Entrevista Semiestructurada y un Cuestionario Sociodemográfico. Los datos de la entrevista fueron transcritos y analizados utilizando el Análisis del Discurso Institucional (AID). Como marco teórico, se utilizaron las contribuciones del psicoanálisis. Los resultados indican que el informe médico-psicológico, para los docentes, es fundamental en la realización del trabajo, así como en la disponibilidad de recursos escolares a los que tiene derecho el alumno.

Palabras-clave: autismo; educación especial; diagnóstico. 


\section{REFERÊNCIAS}

ARAÚJO, F. B. de. A escolarização de alunos com acometimentos orgânicos e psíquicos: educação impossível ou interminável? In: COLÓQUIO INTERNACIONAL DO LEPSI: FORMAÇÃO DE PROFISSIONAIS E A CRIANCA-SUJEITO, 7., 2008, São Paulo. Proceedings online... São Paulo: USP, 2008. Disponível em: $<$ http://www.proceedings.scielo.br/scielo.php?script=sci_arttext\&pid=MSC00000000320080 $00100032 \& \operatorname{lng}=e n \& n r m=a b n>$. Acesso em: 19 out. 2019.

BERNARDINO, Leda Mariza Fischer. A contribuição da Psicanálise para a atuação no campo da educação especial. Estilos da Clínica, v. 12, n. 22, p. 48-67, jun. 2007. Disponível em: < http://www.revistas.usp.br/estic/article/view/46017>. Acesso em: 23 mar. 2020.

BERNARDINO, Leda Mariza Fischer. Mais além do autismo: A psicose infantil e seu não lugar na atual nosografia psiquiátrica. Psicologia Argumento, v. 28, n. 61, p. 111-119, abr./jun. 2010. Disponível em:

<https://periodicos.pucpr.br/index.php/psicologiaargumento/article/view/19617>. Acesso em: 01 mar. 2020.

BERNARDINO, Leda Mariza Fischer. O não decidido da estrutura na infância e a questão do diagnóstico. In: VASQUES, C. K.; MOSCHEN, S. Z. (Orgs.). Psicanálise, Educação e Formação de Professores: construções em rasuras. Porto Alegre: Editora da UFRGS, 2017, p. 29-41.

BERNARDINO, Leda Mariza Fischer. Os "tempos de autismo" e a clínica psicanalítica. Estilos da Clínica, v. 21, n. 2, p. 412-427, ago. 2016. Disponível em: <http://pepsic.bvsalud.org/scielo.php?script=sci_arttext\&pid=S1415-71282016000200008>. Acesso em: 21 mar. 2020.

BRANDÃO, D. B. dos S. R. et al. Da escola para a clínica? In: COLÓQUIO INTERNACIONAL DO LEPSI: O DECLÍNIO DOS SABERES E O MERCADO DE GOZO, 8., 2010, São Paulo. Proceedings online... São Paulo: USP, 2010. Disponível em: < http://www.proceedings.scielo.br/scielo.php?script=sci_arttext\&pid=MSC0000000032010000 100014\&lng=pt\&nrm=abn>. Acesso em: 19 out. 2019.

BRASIL. Ministério da Educação. Secretaria de Educação Continuada, Alfabetização, Diversidade e Inclusão. Nota Técnica $n^{0} 04$ de 23 de janeiro de 2014. Orientação quanto a documentos comprobatórios de alunos com deficiência, transtornos globais do desenvolvimento e altas habilidades/superdotação no Censo Escolar. Brasília: MEC, 2014. Disponível em:

<http://portal.mec.gov.br/index.php?option=com_docman\&view=download\&alias=15898nott04-secadi-dpee-23012014\&category_slug=julho-2014-pdf\&Itemid=30192>. Acesso em: 05 ago. 2019.

BRASIL. Ministério da Educação. Secretaria de Educação Especial. Política Nacional de Educação Especial na Perspectiva da Educação Inclusiva. Brasília: MEC, 2008.

Disponível em: < http://portal.mec.gov.br/arquivos/pdf/politicaeducespecial.pdf>. Acesso em: 05 ago. 2019.

BRIDI, Fabiane Romano de Souza. Políticas de Inclusão Escolar, Diagnóstico e Sujeitos da Educação Especial. In: BAPTISTA, C. R. (Org.). Escolarização e deficiência: configurações Barbarói, Santa Cruz do Sul, n. 58, p.<122-140>, jan/jun 2021 
nas políticas de inclusão escolar. São Carlos: Marquezine \& Manzini - ABPEE, 2015, p. 91105.

BRITO, Mariana Pires. Educação-Especial entre o clínico e o escolar: em busca da terceira margem. 2015. 94 f. Dissertação (Programa de Pós-Graduação em Educação - Mestrado e Doutorado) - Universidade Federal do Rio Grande do Sul, Porto Alegre, 2015.

CAVALCANTI, A. E.; ROCHA, P. S. Autismo: construções e desconstruções. 3. ed. São Paulo: Casa do Psicólogo, 2007.

CHEMAMA, Roland (Org.). Dicionário de Psicanálise Larousse. Tradução de Francisco Franke Settineri. Porto Alegre: Artes Médicas, 1995.

CNS. CONSELHO NACIONAL DE SAÚDE. Resolução no 510, de 7 de abril de 2016.

Diário Oficial da União, Brasília, 24 de maio de 2016, Seção 1, p. 44-46. Disponível em: < http://bvsms.saude.gov.br/bvs/saudelegis/cns/2016/res0510_07_04_2016.html >. Acesso em: 05 ago. 2019.

COSTA, Beethoven Hortencio Rodrigues da; MEDEIROS, Cynthia Pereira de. Demanda diagnóstica na escola: entre querer-o-bem-do-sujeito e a escuta analítica. Estilos da Clínica, v. 23, n. 3, p. 590-610, dez. 2018. Disponível em:

<http://www.revistas.usp.br/estic/article/view/133767>. Acesso em: 18 mar. 2020.

CRESWELL, John W. Método Quantitativos. In: Projeto de pesquisa: métodos qualitativo, quantitativo e misto. Porto Alegre: Artmed, 2010, p. 177-205.

FRASER, Márcia Tourinho Dantas; GONDIM, Sônia Maria Guedes. Da fala do outro ao texto negociado: discussões sobre a entrevista na pesquisa qualitativa. Paidéia, v. 14, n. 28, p. 139-152, mai./ago. 2004. Disponível em: < https://dx.doi.org/10.1590/S0103-

863X2004000200004>. Acesso em: 18 ago. 2019.

FREUD, Sigmund. (1914). Sobre o Narcisismo: uma introdução. In: Edição

Standard Brasileira das Obras Psicológicas Completas de Sigmund Freud, Vol. XIV. Rio de Janeiro: Imago, 1996, p. 77-113.

GUIRADO, Marlene. A Análise Institucional do Discurso como Analítica da

Subjetividade. 2009. 316 f. Tese de Livre-Docência (Instituto de Psicologia da USP) Universidade de São Paulo, São Paulo, 2009.

HEINZ, Maria Marta Vargas de Oliveira. Em direção à escola: desdobramentos da clínica. 2007. 115 f. Dissertação (Programa de Pós-Graduação em Educação - Mestrado e Doutorado) - Universidade Federal do Rio Grande do Sul, Porto Alegre, 2007.

JERUSALINSKY, Julieta. ATENÇÃO: Nem todo sofrimento na primeira infância é autismo, mas precisa ser tratado favorecendo a constituição. In: Autismos e Interfaces da Rede.

Correio APPOA, n. 266, jun. 2017. Disponível em: <

http://www.appoa.com.br/correio/edicao/266/atencao_nem_todo_sofrimento_na_primeira_inf ancia_e_autismo_mas_precisa_ser_tratado_favorecendo_a_constituicao/455>. Acesso em: 18 fev. 2020. 
KUPFER, Maria Cristina Machado. Educação Terapêutica: o que a psicanálise pode pedir à educação. Estilos da Clínica, v. 2, n. 2, p. 53-61, 1997. Disponível em: < http://pepsic.bvsalud.org/scielo.php?script=sci_arttext\&pid=S1415-71281997000200006>. Acesso em: 01 mar. 2020.

KUPFER, Maria Cristina Machado. O Sujeito na psicanálise e na educação: bases para a educação terapêutica. Educação \& Realidade, v. 35, n. 1, p. 265-282, 2010. Disponível em: $<$ https://seer.ufrgs.br/educacaoerealidade/article/view/9371>. Acesso em: 01 mar. 2020.

LERNER, Ana Beatriz Coutinho; VOLTOLINI, Rinaldo. Psicanálise, Ética e Inclusão Escolar. Nuances: Estudos sobre a Educação, v. 26, n. 2, p. 74-92, mai./ago. 2015. Disponível em: < https://revista.fct.unesp.br/index.php/Nuances/article/view/3185>. Acesso em: 05 mar. 2020.

MILMANN, Elaine. Loucos pela escola: o sujeito da desrazão batendo à porta da educação. In: (À) A Margem da Escola. Correio APPOA, n. 114, p. 15-20, jun. 2003. Disponível em: < http://www.appoa.org.br/correio_appoa/a_a_margem_da_escola/463>. Acesso em: 05 abr. 2020.

MILMANN, Elaine. Tecendo os fios da Rede Saúde e Educação: Escolarização de alunos com problemas psíquicos. In: Autismos e Interfaces da Rede. Correio APPOA, n. 266, jun. 2017. Disponível em: <

http://www.appoa.com.br/correio/edicao/266/tecendo_os_fios_da_rede_saude_e_educacao_es colarizacao_de_alunos_com_problemas_psiquicos/460>. Acesso em: 05 abr. 2020.

MOSCHEN, Simone Zanon; GURSKI, Roselene; VASQUES, Carla Karnoppi. De jogos, profanações e gambiarras - por uma educação especial subversiva. Educação, v. 38, n. 2, p. 203-211, nov. 2015. Disponível em: < https://revistaseletronicas.pucrs.br/ojs/index.php/faced/article/view/20046>. Acesso em: 13 out. 2019.

NEVES, Libéria Rodrigues; RAHME, Mônica Maria Farid; FERREIRA, Carla Mercês da Rocha Jatobá. Política de Educação Especial e os Desafios de uma Perspectiva Inclusiva. Educação \& Realidade, v. 44, n. 1, e84853, 2019. Disponível em: $<$ https://www.scielo.br/scielo.php?script=sci_arttext\&pid=S217562362019000100203\&tlng=pt>. Acesso em: 18 mar. 2020.

PEREIRA, Caciana Linhares; FIGUEIREDO, Rita Vieira. Práticas escolares no contexto da proposta inclusiva: reflexões sobre a psicose infantil. Cadernos da Pedagogia, v. 10, n. 20, p. 51-69, jan./jun. 2017. Disponível em: <http://www.cadernosdapedagogia.ufscar.br/index.php/cp/article/viewFile/993/344>. Acesso em: 05 mar. 2020.

PIMENTA, Paula Ramos. Clínica e Escolarização dos Alunos com Transtorno do Espectro Autista (TEA). Educação \& Realidade, v. 44, n. 1, e84859, mar. 2019. Disponível em: < https://www.scielo.br/scielo.php?script=sci_arttext\&pid=S217562362019000100205\&tlng=pt>. Acesso em: 01 mar. 2020.

SILVA, Denise Regina Quaresma da; MELLO, Magda Medianeira; SILVA, Thomas Josué. Reflexões sobre os impasses do diagnóstico psicológico de uma criança na clínica e na escola. Barbarói, Santa Cruz do Sul, n. 58, p.<122-14O>, jan/jun 2021 
Revista de Educação, Ciência e Cultura, v. 20, n. 2, p. 151-166, 2015. Disponível em: < https://revistas.unilasalle.edu.br/index.php/Educacao/article/view/2561 >. Acesso em: $01 \mathrm{mar}$. 2020.

SOUZA, Cássia Fabiane dos Santos; LORENSINI, Sandra Regina Geiss. Planejamento, Avaliação e o Fazer Pedagógico. Revista Multidebates, v. 4, n. 1, p. 45-64, abr. 2020. Disponível em: <http://revista.faculdadeitop.edu.br/index.php/revista/article/view/214>. Acesso em: 09 mai. 2020.

VASQUES, C. K.; MOSCHEN, S.; FRÖHLICH, C. B. Diálogos entre Psicanálise e Educação Especial: uma experiência em formação. In: ANPED SUL: REUNIÃO CIENTÍFICA DA ANPED, X., 2014, Florianópolis. Anais online... Florianópolis: UDESC, 2014. p. 1-18. Disponível em: < http://xanpedsul.faed.udesc.br/arq_pdf/1738-0.pdf>. Acesso em: 18 out. 2019.

VASQUES, Carla Karnoppi. Alice na Biblioteca Mágica: uma leitura sobre o diagnóstico e a escolarização de crianças com psicose e autismo infantil. 2008. 219 f. Tese (Programa de PósGraduação em Educação - Mestrado e Doutorado) - Universidade Federal do Rio Grande do Sul, Porto Alegre, 2008.

VASQUES, Carla Karnoppi. Formas de conhecer em educação especial: o diagnóstico como escudo e lista. Revista Educação PUC-Campinas, v. 20, n. 1, p. 51-59, mai. 2015.

Disponível em: < https://seer.sis.puccampinas.edu.br/seer/index.php/reveducacao/article/view/2943>. Acesso em: 16 mar. 2020.

VASQUES, Carla Karnoppi; MOSCHEN, Simone. Diagnóstico e escolarização: gestos de leitura em Educação Especial. Revista Educação Especial, v. 25, n. 44, p. 435-447, set./dez. 2012. Disponível em: < https://periodicos.ufsm.br/index.php/educacaoespecial/article/view/6530>. Acesso em: 13 out. 2019.

VASQUES, Carla Karnoppi; MOSCHEN, Simone; GURSKI, Roselene. Entre o texto e a vida: uma leitura sobre as políticas de educação especial. Educação e Pesquisa, v. 39, n. 1, p. 81-94, jan./mar. 2013. Disponível em:

$<$ https://www.scielo.br/scielo.php?script=sci_arttext\&pid=S1517-

97022013000100006\&lng=pt\&tlng=pt>. Acesso em: 16 mar. 2020.

VASQUES, Carla. A babel diagnóstica e a escolarização de sujeitos com autismo e psicose infantil: atos de uma leitura. Reflexão e Ação, v. 17, n. 1, p. 7-27, jun. 2009. Disponível em: < https://online.unisc.br/seer/index.php/reflex/article/view/764>. Acesso em: 01 mar. 2020.

VIARO, Renee Volpato; VALORE, Luciana Albanese. Método, Análise e Verdade em Psicologia: sobre uma Análise Institucional do Discurso. Psicologia: Ciência e Profissão, v. 31, n. 4, p. 718-733, 2011. Disponível em: < https://www.scielo.br/scielo.php?script=sci_arttext\&pid=S141498932011000400005\&lng=pt\&tlng=pt>. Acesso em: 18 out. 2019.

VIEIRA, S. L. et al. Multimétodos de coleta de dados no Estudo de Caso Único em Educação e Saúde. In: CONGRESSO IBERO-AMERICANO DE INVESTIGAÇÃO QUALITATIVA, 8., 2019, Lisboa. Proceedings online... Lisboa: Escola Superior de Enfermagem de Lisboa, Barbarói, Santa Cruz do Sul, n. 58, p.<122-140>,jan/jun 2021 
2019. p. 571-579. Disponível em: <

https://proceedings.ciaiq.org/index.php/CIAIQ2019/article/view/2196/>. Acesso em: 18 out. 2019.

VOLTOLINI, Rinaldo. Educação e Psicanálise. Rio de Janeiro: Zahar, 2011, 82 p. (Coleção Passo-a-Passo, 93).

VORCARO, Angela. O tratamento do autismo: notas introdutórias. Analytica, v. 5, n. 9, p. 430, jul./dez. 2016. Disponível em: <

http://www.seer.ufsj.edu.br/index.php/analytica/article/view/2038>. Acesso em: 05 mar.

2020.

Data de recebimento: 06/08/2020

Data de aceite: 03/01/2021

\section{Sobre os autores:}

Wilian Gomes da Silva é Acadêmico de Psicologia da Universidade Luterana do Brasil (ULBRA/RS), Campus Gravataí. Cursando o último semestre do referido curso. Atualmente, realiza Estágio Curricular na ênfase 'Processos Clínicos e Psicoterápicos (Psicanálise)' no Núcleo Integrado de Psicologia (NIP) da ULBRA/Gravataí. Endereço Eletrônico: wilian.silva@rede.ulbra.br

Simone Regina Sandri Modesti é Psicóloga da Fundação de Articulação e Desenvolvimento de Políticas Públicas para PcD e PcAH (FADERS). Docente do Curso de Psicologia da Universidade Luterana do Brasil (ULBRA), Campus Gravataí/RS. Mestra em Psicologia do Desenvolvimento pela Universidade Federal do Rio Grande do Sul (UFRGS). Endereço Eletrônico: sirsandri@gmail.com 